\title{
1 Balancing Open Science and Data Privacy in the Water Sciences
}

2 Authors: Samuel C. Zipper ${ }^{1}$, Kaitlin Stack Whitney ${ }^{2}$, Jillian M. Deines ${ }^{3}$, Kevin M. Befus ${ }^{4}$, Udit 3 Bhatia $^{5,6}$, Sam J. Albers ${ }^{7}$, Janice Beecher ${ }^{8}$, Christa Brelsford ${ }^{9}$, Margaret Garcia ${ }^{10}$, Tom Gleeson ${ }^{1}$, $4 \quad$ Frances O'Donnell ${ }^{11}$, David Resnik ${ }^{12}$, Edella Schlager ${ }^{13}$

\section{Affiliations:}

6 1. Department of Civil Engineering, University of Victoria, Victoria BC Canada

7 2. Science, Technology, and Society Department, Rochester Institute of Technology, 8 Rochester NY USA

9 3. Department of Earth Systems Science and Center on Food Security and the Environment, Stanford University, Stanford CA USA

4. Department of Civil and Architectural Engineering, University of Wyoming, Laramie WY USA

5. Civil and Environmental Engineering, Northeastern University, Boston MA USA

6. Civil Engineering, Indian Institute of Technology, Gandhinagar India

7. Groundwater, Hydrology and Hydrometric Programs, Ministry of Environment and Climate Change Strategy, British Columbia Provincial Government

8. Institute of Public Utilities, Michigan State University, East Lansing MI USA

9. Oak Ridge National Laboratory, Oak Ridge TN USA

10. School of Sustainable Engineering and the Built Environment, Arizona State University, Tempe AZ USA

11. Department of Civil Engineering, Auburn University, Auburn AL USA

12. National Institute of Environmental Health Sciences, National Institutes of Health, Research Triangle Park, NC USA

13. School of Government and Public Policy, University of Arizona, Tucson AZ USA 


\section{Key Points}

- Natural scientists have little guidance to deal with privacy concerns for open science which are inherent in socio-environmental research.

- Hydrology data with potential privacy concerns include high-resolution spatial data, consumer data, and digital trace data.

- Scientists should continue to share data openly while proactively addressing privacy concerns via ethical data management and sharing.

\section{Abstract}

36 Open science practices such as publishing data and code are transforming water science by

37 enabling synthesis and enhancing reproducibility. However, as research increasingly bridges the

38 physical and social science domains (e.g., socio-hydrology), there is the potential for well-

39 meaning researchers to unintentionally violate the privacy and security of individuals or

40 communities by sharing sensitive information. Here, we identify the contexts in which privacy

41 violations are most likely to occur, such as working with high-resolution spatial data (e.g., from

42 remote sensing), consumer data (e.g., from smart meters), and/or digital trace data (e.g., from

43 social media). We also suggest practices for identifying and addressing privacy concerns at the

44 individual, institutional, and disciplinary levels. We strongly advocate that the water science

45 community continue moving toward open science and socio-environmental research and that

46 progress toward these goals be rooted in open and ethical data management. 


\section{Emerging and intersecting trends}

49 Widespread adoption of open science practices such as sharing data via public repositories advances water science by enabling new types of synthesis-based science and promoting reproducibility (Gil et al., 2016; Munafò et al., 2017; Powers \& Hampton, 2018). In the earth sciences, this push is led by the American Geophysical Union's policy to make data and code available for all papers under the Findable, Accessible, Interoperable, and Reusable (FAIR) standards (Stall et al., 2017; Wilkinson et al., 2016). However, gradual adoption of open science practices is converging with two other trends: (i) growth in research investigating the relationships between humans and the water cycle as part of a broader movement of socioenvironmental research including socio-hydrology and enhanced collaboration with social scientists (Flint et al., 2017; Konar et al., 2019; Sivapalan et al., 2012; Srinivasan et al., 2017; Wagener et al., 2010); and (ii) exponential growth in computing power and sensor technology allowing data collection and analyses with unprecedented spatial and temporal granularity. These advances are essential for understanding the water cycle of the Anthropocene, and we unequivocally encourage continued progress along these paths within the water science community.

At the intersection of open science, socio-environmental research, and high-resolution data, however, there is an emerging potential to violate the privacy of uninformed and/or nonconsenting individuals and communities (Hartter et al., 2013; Grossman et al., 2015). Researchers have a responsibility to acknowledge and anticipate the risk inherent in open data and accordingly minimize harm to stakeholders potentially impacted by their research. While the natural inclination of many well-meaning researchers (many of the present authors included) is to focus on the societal benefits of data sharing, there are also potential risks arising from unintended applications of open data. These risks can magnify when researchers lack cultural understanding of and sensitivity toward communities to which they do not belong. In some cases, people or companies in positions of power have taken advantage of open data at the expense of the intended beneficiaries of the shared data (Donovan, 2012; Gurstein, 2011; McClean, 2011). For instance, the digitization of land records in Karnataka, India, was promoted as a tool to democratize access to information, but instead allowed wealthy landowners with more financial resources to consolidate power and capitalize on these new data (Donovan, 2012). As seen through the lens of environmental justice, these concerns are particularly acute when working with historically disadvantaged groups such as impoverished communities and indigenous peoples (Christen, 2015; Radin, 2017; Brugge \& Missaghian, 2006).

Though data-sharing mandates make exemptions for potentially sensitive datasets, natural scientists are rarely trained in navigating ethical, privacy, and data security issues. Our primary objective here is to highlight potential privacy concerns specific to hydrology at the intersection recommend practices for water science researchers interested in adopting open science principles. 


\section{Sensitive data}

Sensitive data include private or personal information as well as information that, whether in isolation or combined with other datasets, can be linked to specific, non-consenting individuals or communities. Researchers should be cautious when their research meets the definition of "human subject research", defined in the USA as including "a living individual about whom a research investigator... obtains data through 1) intervention or interaction with the individual, or 2) identifiable private information" (32 C.F.R. 219.102(f)). However, the definition of "human subject research" focuses on the individual subjects of research, and there may also be situations where concerns arise about datasets dealing with communities, households, or other units. This may include third parties who are not the specific human subjects - for example, family members of study participants (Resnik \& Sharp, 2006) - or broader communities even when individual data are protected (Radin, 2017).

We highlight three general categories of data used by the water science community where privacy concerns are most likely to arise: high-resolution spatial data, consumer data, and digital trace data (Figure 1). We argue that harm to individuals or communities will infrequently come directly from the researchers publishing studies on the data themselves but rather from third parties who could use the data for profit, coercion, or regulatory action (Lagos \& Polonetsky, 2013); analogously, poachers have used species location data from scientific papers for wildlife trafficking (Lindenmayer \& Scheele, 2017).

\section{High-Resolution Spatial Data}

High-resolution spatial data include satellite data (and derived products), outputs of hydrological models, and other geospatial datasets. Geospatial data are commonly used in the hydrologic sciences, and unmanned aerial vehicles (i.e., drones; Kelleher et al., 2018), traffic/surveillance cameras (Leitão et al., 2018; Jiang et al., 2019), and increasing access to satellite data are likely to make these data less costly to collect and more widely available. Despite not meeting traditional definitions of human subject research, this type of data could be sensitive at the individual and community levels (Rissman et al., 2017). For example, 30\% of Iowa farmers surveyed felt that collecting geospatial data on private land was an invasion of privacy (Arbuckle Jr., 2013).

At the individual level, high-resolution spatial data can be used to track or identify private activities. For example, a farmer's operations, finances, and land valuation may be inferred by mapping agricultural practices such as cropping patterns, management, and productivity (Deines et al., 2017, 2019; Kang et al., 2016; Seifert et al., 2018; Zipper et al., 2015, 2017). Similar datasets containing information on illegal or quasi-legal activities such as marijuana cultivation could be used by law enforcement agencies (Bauer et al., 2015; Butsic et al., 2017, 2018). Analysis of wastewater at specific points can reveal information about the activities and health of either individuals or communities via chemical tracers of illegal drugs, prescription medicine, or 
other biomarkers (Hall et al., 2012; Choi et al., 2018). At the community level, high-resolution hydrological data such as that produced by flood risk studies, for example following hurricanes (Bin \& Landry, 2013) or wildfire (Mueller et al., 2009), can lower property values. Similarly, sharing household level water quality data may negatively impact property values or insurance rates at the individual and neighborhood levels; this was a concern in Flint, Michigan following the water crisis. Water infrastructure locational data can be sensitive due to the potential for threats to water safety and quality (Copeland \& Cody, 2007; Van Leuven, 2011). Also potentially concerning are culturally or ecologically sensitive geospatial information, which can lead to resource degradation and harm from ecotourism (Lindenmayer \& Scheele, 2017; Lunghi et al., 2019; McCoy, 2017; Vaz, 2008).

Given that many geospatial datasets quantify features of the land surface that could be observed by someone on the ground (e.g., land cover, irrigation practices), it is challenging to draw the line between properties of the landscape and private information. The notion of a 'reasonable expectation of privacy' for people, a legal standard in the US and the EU among other regions, can come into conflict with the preponderance of high-resolution spatial data, and satellite and aerial image datasets may be privacy and liability risks to individuals (Craig, 2007). Some court cases have ruled on issues with potential conceptual application. For example, the United States of America v. Vargas (2014) decision ruled that an individual had an expectation to privacy in and around the front yard of their home and thus surveillance in this area was a violation of their rights. With similar types of data in a research context, there is no clear-cut answer or deciding body, but legal rights and protections might still apply and the ethical implications remain.

146 Potentially sensitive consumer data include household consumption of water or electricity, or other variables that are of sufficient spatial or temporal resolution to be identified with and provide information about an individual or household (McKenna et al., 2012). While these data often have a spatial component to them, they are distinct from the previous category in that they quantify resource consumption (Helveston, 2015). The potential to monetize consumer information raises issues of data ownership, along with privacy.

Consumer data gaining traction in the water sciences are derived from "smart meters," which are electricity or water meters that can transmit data back to the utility at hourly or finer temporal resolutions. Smart water meters are relatively less common than smart electricity meters (Cominola et al., 2015), but are potentially valuable for understanding water use, promoting conservation, and managing water supply in urban areas (Britton et al., 2013; Cardell-Oliver et al., 2016). However, data provided by smart meters can also reveal household-level activity, namely when residents are home and using energy or water (Cole \& Stewart, 2013; MolinaMarkham et al., 2010; Sankar et al., 2013). 
While water-related research is often fairly unintrusive, consumer water data can enable undesired surveillance. Meter data may be used in law enforcement (Douris, 2017) and searched by the police without a warrant (Naperville Smart Meter Awareness v. City of Naperville, 2018), as for identifying illegal marijuana grow operations (US7402993B2, 2008). Some cities publicize the highest water users during droughts to "name and shame" consumers into conserving water resources (Glionna, 2015; Horwath, 2015), which, regardless of perceived efficacy, violates personal privacy and allowable choice, and may not actually be necessary if less individualized tools for shaping consumption behavior (such as pricing and information campaigns) are in place.

\section{Digital Trace Data}

Digital trace data include deliberate online activities (e.g., social media, web browsing) as well as web-enabled technologies (e.g., the 'Internet of Things') (Howison et al., 2011), and can be divided into two groups: passively and actively contributed. Passively contributed data are posted to the internet without the intent or knowledge for potential scientific use (most social media data), while actively contributed data are contributed to a specific project (most crowdsourced citizen science research). Both types of data have been used for hydrologic research. Examples of passively contributed studies include generating long-term water level records from YouTube videos (Michelsen et al., 2016), estimating snowpack from public web images (Giuliani et al., 2016), and reconstructing crop planting dates from Twitter postings (Zipper, 2018). Examples of actively contributed studies include citizen science projects focused on streamflow monitoring (Fienen \& Lowry, 2012; Lowry \& Fienen, 2013), storm identification (Zhou \& Xu, 2017), and flood extent mapping (Le Coz et al., 2016; Yu et al., 2016).

Both actively and passively collected data can violate individual or community privacy (Wu, 2013). Data derived from social media present particular challenges. The State of New York recently allowed insurance companies to use social media data to help determine customer premiums (Scism, 2019). While research is permitted within Twitter's terms of service, the lack of comfort and awareness among users highlights both the public's growing unease with researchers using digital trace data, and the fact that individuals often accept user agreements that they do not read or fully understand (Bashir et al., 2015; Editorial Board, 2019). Although social media data are increasingly used in environmental research (Daume, 2016; Zipper, 2018), only $17 \%$ of respondents in a recent survey indicated that they were comfortable with their tweets being used without being informed (Fiesler \& Proferes, 2018).

The ethical responsibility of researchers may thus call for a higher standard than either the letter of law or terms of service to protect individual privacy rights, autonomy, and well-being (Ghermandi \& Sinclair, 2019). The good intentions of researchers cannot prevail over the interests of human subjects; even a sense of social purpose should not be used to rationalize circumventing ethical requirements and procedures. Given the pace of technological change, and lagging governmental regulation, self-regulation by the scientific community is needed. 


\section{Addressing privacy concerns with open and ethical data management}

199

200

201

202

203

204

205

206

207

208

209

210

211

212

213

214

215

216

217

218

219

220

221

222

223

224

225

226

227

228

229

230

231

232

233

234

235

Despite challenges, we do not suggest that data should never be openly shared. Rather, our goal is to encourage water scientists to practice open and ethical data management in which researchers recognize and address privacy and security considerations prior to collecting data and proactively plan for data sharing throughout the research process (Meyer, 2018). Guidance can be drawn from disciplines including medical science, utilities research, computer science, economics, psychology, and law as well as previous work integrating biophysical and social aspects of water science (Flint et al., 2017). Given the diversity of data used across these fields, accepted practices will vary widely (Lupia \& Elman, 2014), and we focus on broadly applicable general principles which may be relevant to the water science community. A recent synthesis proposed a decision tree for biodiversity data which considers the potential benefits and risks of sharing (Tulloch et al., 2018); we present a similar approach in Figure 2. However, legal constraints vary (Klass \& Wilson, 2016), as only $58 \%$ of countries currently have data privacy legislation (United Nations, 2018), and researchers should consider their local context.

\section{Institutional and Community Resources}

First and foremost, we encourage water scientists to consult available institutional resources. Prior to beginning a study, investigators should evaluate whether it could be classified as human subjects research (Figure 2). Institutional review boards in the United States, research ethics committees in the European Union, and their equivalents in other nations and the private sector set requirements for obtaining informed consent from research subjects and stipulations for protecting data confidentiality and privacy (Resnik, 2018). Colleagues can also be an invaluable resource; by collaborating with social scientists with experience navigating these issues, hydrologists can co-develop research topics, methods, and data management plans which ask and answer socio-environmental questions in an ethical and reproducible manner (Flint et al., 2017). Additional resources found at many institutions include legal counsels, privacy or information officers, research librarians, and research ethicists. Researchers and their institutions may need to enter into agreements to ensure protection of data provided by others, such as meter data collected by utilities. As data privacy and security issues evolve, so will public opinion and regulatory policies about which researchers need to be aware.

There is also a need to think beyond the individual when sharing data that may lead to harm for a group of individuals or a community. Dickert \& Sugarman (2005) suggest a community consultation process which is well-suited to the water sciences (Figure 2): (1) prior to beginning a project, researchers should identify potential risks to individuals and the community; (2) the community being studied should benefit in some way; (3) potentially affected parties should be given opportunity to shape the project; and (4) communities share in the responsibility for the project. These steps require meaningful engagement with the stakeholder community prior to the onset of research to identify potential benefits and harms, which can then be addressed collaboratively. Although desirable, it may be prohibitive to obtain individual consent, in which 
case this process might be conducted at the community level via consultation with elected representatives, community leaders, and open public meetings, such as town halls, as well as focus groups and opinion surveys. The challenge is to establish community-level authority and rules for decision-making.

Additional concerns arise when affected communities include Indigenous peoples. Sovereign nations often have their own research protocols, which may be more stringent than institutional requirements (Brugge and Missaghian, 2006). Some Indigenous nations or people consider data collected on their land to be tribal property and do not permit these data to be shared openly (Chief et al., 2016). The emerging concept of Indigenous data sovereignty asserts that Indigenous groups have jurisdiction over the collection, ownership, and downstream use of data collected by or about their own peoples or land (Rainie et al., 2017). Thus, a collaborative approach should guide the entire research process (David-Chavez and Gavin, 2018), including discussions about data security, ownership, and sharing (Chief et al., 2018; Whyte, 2017).

To meet the diverse needs of the water research community, legal frameworks should be informed and supplemented by community, professional, and scientific standards, and vice versa. At the funding stage, many agencies require the submission of data management plans, and these should be required to address potential privacy and security concerns prior to the onset of research. At the publication stage, journals could augment data sharing requirements by requiring a written data privacy and security statement as part of the submission process; similar recommendations have been made by the wildlife research community to deal with inconsistent standards across institutional boundaries (Field et al., 2019). At the archiving stage, community data repositories (such as the Consortium of Universities for the Advancement of Hydrologic Science, Inc. HydroShare portal) can develop data privacy guidelines and require researchers to submit data privacy statements; even the simple step of requiring users to affirm that submitted data are legally allowed and do not contain personally identifiable information can be effective (King, 2007). To further assist early-career scientists, responsible human subjects training should be integrated into graduate programs in the water sciences and departmental handbooks and protocols should include information about institutional resources to improve both the technical and ethical data literacy. As in other areas of ethical training, opportunities or requirements for continuing education should also be provided. Finally, standards should be enforced, and breaches should be penalized.

268 Ethical data sharing requires transforming data via aggregation or other means to ensure that it is no longer identifiable at a level that jeopardizes privacy and cannot by 'de-anonymized' when combined with other datasets (Helveston, 2015; Wu, 2013). All anonymization techniques will inherently cause a loss in the information content and utility of the data (Antonatos et al., 2018). To minimize the effect of this loss and meet FAIR standards, it is critical to also include detailed information about the anonymization procedure via metadata and sharing code, ideally using 
open-source tools integrating version control for transparency, to allow for interoperability and usability by other researchers (Bakker, 2019; Lowndes et al., 2017; Stagge et al., 2019). When possible, researchers should leave jurisdiction of sensitive data to the agencies responsible for collecting and warehousing these data; where there is no such organization, they should provide synthetic examples of the data so that others can understand and replicate the anonymization procedure.

Spatially identifiable information can be stripped from data prior to publication without compromising reproducibility if the spatial location is not critical to the study. McKenna et al. (2012) suggest, for example, that smart meter data can be used without compromising individual privacy by aggregating data to sufficiently coarse spatial or temporal scales so that individual activities cannot be inferred. Alternately, where the spatial relation among data points is important but absolute geographic coordinates are not, geographic coordinates can be scaled to preserve relative relationships between points (Stack Whitney et al., 2016) or data can be converted to a non-spatial network with mapped relationships between nodes (individuals) and elements (data points) (Figure 1). A network perspective can yield insights about characteristics of water systems without revealing information about individual users (Barabási \& Albert, 1999; Perelman \& Ostfeld, 2011). Where spatial location is critical, aggregation is necessary. For example, urban water use data are often aggregated to the census block or coarser for research purposes (Brelsford \& Abbott, 2017; Breyer et al., 2012, 2018). Other high-resolution data providing evidence of water conditions or human activity (including water use, water quality impairment, and illegal activities) may also require aggregation (Hall et al., 2012; Prichard et al., 2014). Aggregation protects individual privacy but limits the ability of researchers to explore fine-scale spatial and behavioral dynamics.

Digital trace data are particularly challenging to anonymize, since social media platforms such as Twitter are searchable; even if a researcher strips identifying information (such as user names) from the database, data can easily be 'de-anonymized' via searching for the text or observing network structure (Ayers et al., 2018). In most studies, data at the individual level are unnecessary, since researchers are primarily interested in population-level statistics, and derived statistics can be extracted from the dataset and shared without the accompanying raw data. Even more directly, the metric quantified from each piece of digital trace data could be shared. For example, a study using tweets to study the timing of irrigation could share the date, county, and crop-type mentioned without sharing the specific field-level geolocation or raw tweet text.

\section{Conclusions}

307 Increased adoption of open science principles and availability of high-resolution data are 308 transforming socio-environmental and socio-hydrological science for the better. At the 309 convergence of these trends are emerging challenges related to ensuring reproducibility without 310 inadvertently causing harm to individuals or communities. As new data sources and 311 interdisciplinary research continues to grow, self-reflection as a community is necessary to 
312 ensure that privacy and security are dealt with proactively to maintain trust in the hydrologic 313 sciences among all stakeholders and the public we serve.

\section{Acknowledgments}

315 This paper arose from a workshop at the Santa Fe Institute that was supported by the National 316 Science Foundation under Grant No. 1735884. No data were used in this manuscript but if any 317 were, we definitely would have openly published them! 


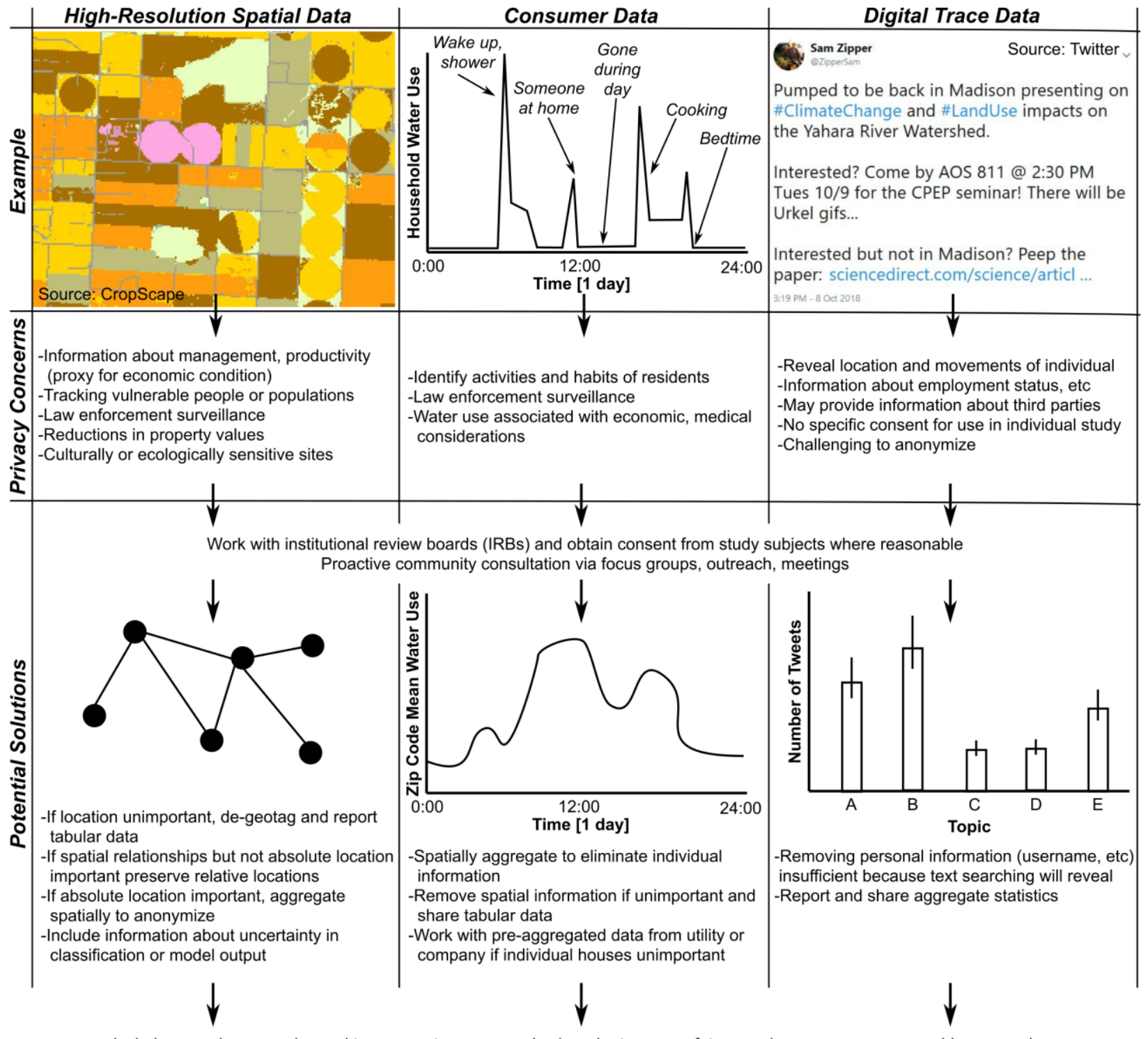

Include procedure or code used to aggregate or summarize in order to ensure future analyses can use comparable approach

321 Figure 1. Examples of data types with potential privacy concerns, and recommended practices. Left: High spatial resolution data as provided by the US Department of Agriculture's CropScape portal for the Cropland Data Layers (Han et al., 2012), which uses satellite data to map agricultural land use and crop types at 30 square meter resolution. Center: Example high temporal resolution household water use data from a smart meter with annotated information that can be inferred. Right: Example tweet including potentially concerning information (in this case, travel patterns). 


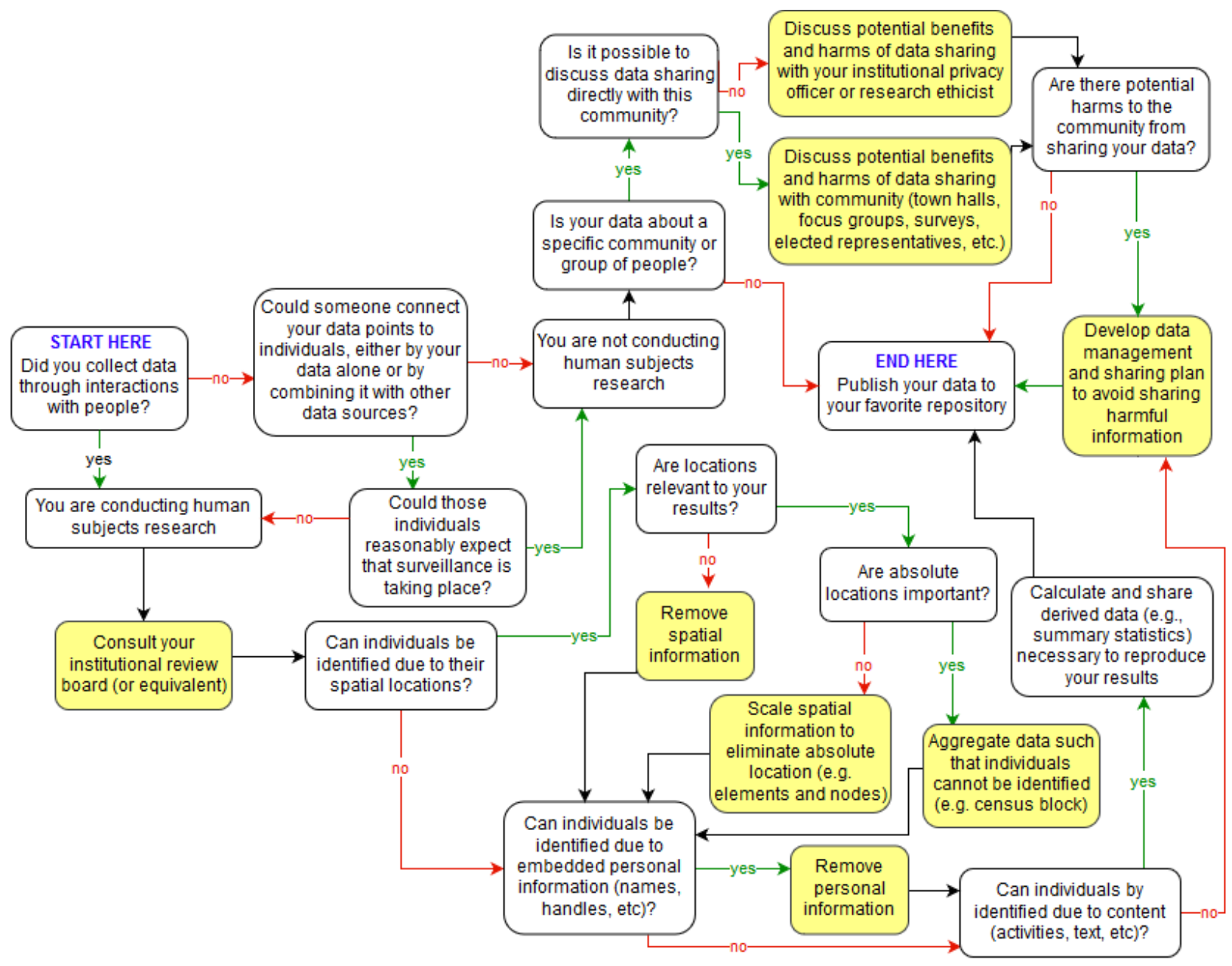

Figure 2. Potential decision tree researchers can use to evaluate practices for sharing their data.

\section{References}

Antonatos, S., Braghin, S., Holohan, N., Gkoufas, Y., \& Mac Aonghusa, P. (2018). PRIMA: An End-to-End Framework for Privacy at Scale. In 2018 IEEE 34th International Conference on Data Engineering (ICDE) (pp. 1531-1542). IEEE.

Arbuckle Jr., J. G. (2013). Farmer Attitudes toward Proactive Targeting of Agricultural Conservation Programs. Society \& Natural Resources, 26(6), 625-641. https://doi.org/10.1080/08941920.2012.671450

Ayers, J. W., Caputi, T. L., Nebeker, C., \& Dredze, M. (2018). Don't quote me: reverse identification of research participants in social media studies. Npj Digital Medicine, 1(1), 30. https://doi.org/10.1038/s41746-018$0036-2$

Bakker, M. (2019). Data-Sharing Requires Script-Sharing. Groundwater. https://doi.org/10.1111/gwat.12852

Barabási, A.-L., \& Albert, R. (1999). Emergence of Scaling in Random Networks. Science, 286(5439), 509-512. https://doi.org/10.1126/science.286.5439.509

Bauer, S., Olson, J., Cockrill, A., Hattem, M. van, Miller, L., Tauzer, M., \& Leppig, G. (2015). Impacts of Surface Water Diversions for Marijuana Cultivation on Aquatic Habitat in Four Northwestern California Watersheds. PLOS ONE, 10(3), e0120016. https://doi.org/10.1371/journal.pone.0120016 Bin, O., \& Landry, C. E. (2013). Changes in implicit flood risk premiums: Empirical evidence from the housing 
market. Journal of Environmental Economics and Management, 65(3), 361-376. https://doi.org/10.1016/j.jeem.2012.12.002

Brelsford, C., \& Abbott, J. K. (2017). Growing into Water Conservation? Decomposing the Drivers of Reduced Water Consumption in Las Vegas, NV. Ecological Economics, 133, 99-110. https://doi.org/10.1016/j.ecolecon.2016.10.012

Breyer, B., Chang, H., \& Parandvash, G. H. (2012). Land-use, temperature, and single-family residential water use patterns in Portland, Oregon and Phoenix, Arizona. Applied Geography, 35(1-2), 142-151. https://doi.org/10.1016/j.apgeog.2012.06.012

Breyer, B., Zipper, S. C., \& Qiu, J. (2018). Sociohydrological Impacts of Water Conservation Under Anthropogenic Drought in Austin, TX (USA). Water Resources Research, 54(4), 3062-3080. https://doi.org/10.1002/2017WR021155

Britton, T. C., Stewart, R. A., \& O’Halloran, K. R. (2013). Smart metering: enabler for rapid and effective post meter leakage identification and water loss management. Journal of Cleaner Production, 54, 166-176. https://doi.org/10.1016/j.jclepro.2013.05.018

Brugge, D., \& Missaghian, M. (2006). Protecting the Navajo people through tribal regulation of research. Science and Engineering Ethics, 12(3), 491-507. https://doi.org/10.1007/s11948-006-0047-2

Butsic, V., Schwab, B., Baumann, M., \& Brenner, J. C. (2017). Inside the Emerald Triangle: Modeling the Placement and Size of Cannabis Production in Humboldt County, CA USA. Ecological Economics, 142, 70-80. https://doi.org/10.1016/j.ecolecon.2017.06.013

Butsic, V., Carah, J. K., Baumann, M., Stephens, C., \& Brenner, J. C. (2018). The emergence of cannabis agriculture frontiers as environmental threats. Environmental Research Letters, 13(12), 124017. https://doi.org/10.1088/1748-9326/aaeade

Cardell-Oliver, R., Wang, J., \& Gigney, H. (2016). Smart Meter Analytics to Pinpoint Opportunities for Reducing Household Water Use. Journal of Water Resources Planning and Management, 142(6), 04016007. https://doi.org/10.1061/(ASCE)WR.1943-5452.0000634

Chief, K., Meadow, A., \& Whyte, K. (2016). Engaging Southwestern Tribes in Sustainable Water Resources Topics and Management. Water, 8(8), 350. https://doi.org/10.3390/w8080350

Choi, P. M., Tscharke, B. J., Donner, E., O’Brien, J. W., Grant, S. C., Kaserzon, S. L., ... Mueller, J. F. (2018). Wastewater-based epidemiology biomarkers: Past, present and future. TrAC Trends in Analytical Chemistry, 105, 453-469. https://doi.org/10.1016/j.trac.2018.06.004

Christen, K. (2015). Tribal Archives, Traditional Knowledge, and Local Contexts: Why the "s" Matters. Journal of Western Archives, 6(1). Retrieved from https://digitalcommons.usu.edu/westernarchives/vol6/iss1/3

Cole, G., \& Stewart, R. A. (2013). Smart meter enabled disaggregation of urban peak water demand: precursor to effective urban water planning. Urban Water Journal, 10(3), 174-194. https://doi.org/10.1080/1573062X.2012.716446

Cominola, A., Giuliani, M., Piga, D., Castelletti, A., \& Rizzoli, A. E. (2015). Benefits and challenges of using smart meters for advancing residential water demand modeling and management: A review. Environmental Modelling \& Software, 72, 198-214. https://doi.org/10.1016/j.envsoft.2015.07.012

Copeland, C., \& Cody, B. A. (2007). Terrorism and security issues facing the water infrastructure sector. In E. V. Linden (Ed.), Focus on Terrorism. Nova Publishers.

Craig, B. (2007). Online Satellite and Aerial Images: Issues and Analysis. North Dakota Law Review, 83, 547.

David-Chavez, D. M., \& Gavin, M. C. (2018). A global assessment of Indigenous community engagement in climate research. Environmental Research Letters, 13(12), 123005. https://doi.org/10.1088/17489326/aaf300

Deines, J. M., Kendall, A. D., \& Hyndman, D. W. (2017). Annual Irrigation Dynamics in the U.S. Northern High Plains Derived from Landsat Satellite Data. Geophysical Research Letters, 44(18), 9350-9360. https://doi.org/10.1002/2017GL074071

Deines, J. M., Kendall, A. D., Butler, J. J., \& Hyndman, D. W. (2019). Quantifying irrigation adaptation strategies in response to stakeholder-driven groundwater management in the US High Plains Aquifer. Environmental 
Research Letters, 14(4), 044014. https://doi.org/10.1088/1748-9326/aafe39

Dickert, N., \& Sugarman, J. (2005). Ethical Goals of Community Consultation in Research. American Journal of Public Health, 95(7), 1123-1127. https://doi.org/10.2105/AJPH.2004.058933

Donovan, K. P. (2012). Seeing Like a Slum: Towards Open, Deliberative Development. Georgetown Journal of International Affairs, 13(1), 97-104.

Douris, C. (2017, May 9). Balancing Access to Electricity Data and Privacy Concerns. Retrieved September 21, 2018, from https://www.lexingtoninstitute.org/balancing-access-electricity-data-privacy-concerns/

Field, K. A., Paquet, P. C., Artelle, K., Proulx, G., Brook, R. K., \& Darimont, C. T. (2019). Publication reform to safeguard wildlife from researcher harm. PLOS Biology, 17(4), e3000193. https://doi.org/10.1371/journal.pbio.3000193

Fienen, M. N., \& Lowry, C. S. (2012). Social.Water-A crowdsourcing tool for environmental data acquisition. Computers \& Geosciences, 49, 164-169. https://doi.org/10.1016/j.cageo.2012.06.015

Flint, C. G., Jones, A. S., \& Horsburgh, J. S. (2017). Data Management Dimensions of Social Water Science: The iUTAH Experience. JAWRA Journal of the American Water Resources Association, 53(5), 988-996. https://doi.org/10.1111/1752-1688.12568

Ghermandi, A., \& Sinclair, M. (2019). Passive crowdsourcing of social media in environmental research: A systematic map. Global Environmental Change, 55, 36-47. https://doi.org/10.1016/j.gloenvcha.2019.02.003

Gil, Y., David, C. H., Demir, I., Essawy, B. T., Fulweiler, R. W., Goodall, J. L., ... Yu, X. (2016). Toward the Geoscience Paper of the Future: Best practices for documenting and sharing research from data to software to provenance. Earth and Space Science, 3(10), 388-415. https://doi.org/10.1002/2015EA000136

Giuliani, M., Castelletti, A., Fedorov, R., \& Fraternali, P. (2016). Using crowdsourced web content for informing water systems operations in snow-dominated catchments. Hydrology and Earth System Sciences, 20(12), 5049-5062. https://doi.org/10.5194/hess-20-5049-2016

Glionna, J. M. (2015, October 30). Las Vegas outs its water hogs -- at least when asked. Los Angeles Times. Retrieved from http://www.latimes.com/nation/la-na-vegas-water-hogs-20151030-story.html

Grossman, D., Buckley, N., \& Doyle, M. (2015). Data Intelligence for 21st Century Water Management: A Report from the 2015 Aspen-Nicholas Water Forum. Aspen-Nicholas Water Forum. Retrieved from https://www.aspeninstitute.org/publications/data-intelligence-21st-century-water-management-report-2015aspen-nicholas-water-forum/

Gurstein, M. B. (2011). Open data: Empowering the empowered or effective data use for everyone? First Monday, 16(2). https://doi.org/10.5210/fm.v16i2.3316

Hall, W., Prichard, J., Kirkbride, P., Bruno, R., Thai, P. K., Gartner, C., .. Mueller, J. F. (2012). An analysis of ethical issues in using wastewater analysis to monitor illicit drug use. Addiction, 107(10), 1767-1773. https://doi.org/10.1111/j.1360-0443.2012.03887.x

Han, W., Yang, Z., Di, L., \& Mueller, R. (2012). CropScape: A Web service based application for exploring and disseminating US conterminous geospatial cropland data products for decision support. Computers and Electronics in Agriculture, 84, 111-123. https://doi.org/10.1016/j.compag.2012.03.005

Hartter, J., Ryan, S. J., MacKenzie, C. A., Parker, J. N., \& Strasser, C. A. (2013). Spatially Explicit Data: Stewardship and Ethical Challenges in Science. PLOS Biology, 11(9), e1001634. https://doi.org/10.1371/journal.pbio.1001634

Helveston, M. N. (2015). Consumer Protection in the Age of Big Data. Wash. UL Rev., $93,859$.

Horwath, J. (2015, March 31). Top 10 WATER GUZZLERS. Santa Fe Reporter. Retrieved from http://www.sfreporter.com/news/coverstories/2015/03/31/top-10-water-guzzlers/

Howison, J., Wiggins, A., \& Crowston, K. (2011). Validity issues in the use of social network analysis with digital trace data. Journal of the Association for Information Systems, 12(12), 767.

Jiang, S., Babovic, V., Zheng, Y., \& Xiong, J. (2019). Advancing Opportunistic Sensing in Hydrology: A Novel Approach to Measuring Rainfall With Ordinary Surveillance Cameras. Water Resources Research, In press. https://doi.org/10.1029/2018WR024480 
Kang, Y., Özdoğan, M., Zipper, S. C., Román, M. O., Walker, J., Hong, S. Y., ... Loheide, S. P. (2016). How universal is the relationship between remotely sensed vegetation indices and crop leaf area index? A global assessment. Remote Sensing, 8(7), 597. https://doi.org/10.3390/rs8070597

Kelleher, C. A., Scholz, C. A., Condon, L. E., \& Reardon, M. (2018). Drones in Geoscience Research: The Sky Is the Only Limit. Eos, 99. https://doi.org/10.1029/2018EO092269

King, G. (2007). An Introduction to the Dataverse Network as an Infrastructure for Data Sharing. Sociological Methods and Research, 36, 173-199.

Klass, A. B., \& Wilson, E. J. (2016). Remaking Energy: The Critical Role of Energy Consumption Data. Cal. L. Rev., 104, 1095.

Konar, M., Garcia, M., Sanderson, M. R., Yu, D. J., \& Sivapalan, M. (2019). Expanding the Scope and Foundation of Sociohydrology as the Science of Coupled Human-Water Systems. Water Resources Research, 55(2), 874-887. https://doi.org/10.1029/2018WR024088

Lagos, Y., \& Polonetsky, J. (2013). Public v. Nonpublic Data: The Benefits of Administrative Controls. Stan. L. Rev. Online, 66, 103.

Le Coz, J., Patalano, A., Collins, D., Guillén, N. F., García, C. M., Smart, G. M., ... Braud, I. (2016). Crowdsourced data for flood hydrology: Feedback from recent citizen science projects in Argentina, France and New Zealand. Journal of Hydrology, 541, Part B, 766-777. https://doi.org/10.1016/j.jhydrol.2016.07.036

Leitão, J. P., Peña-Haro, S., Lüthi, B., Scheidegger, A., \& Moy de Vitry, M. (2018). Urban overland runoff velocity measurement with consumer-grade surveillance cameras and surface structure image velocimetry. Journal of Hydrology, 565, 791-804. https://doi.org/10.1016/j.jhydrol.2018.09.001

Lindenmayer, D., \& Scheele, B. (2017). Do not publish. Science, 356(6340), 800-801. https://doi.org/10.1126/science.aan1362

Lowndes, J. S. S., Best, B. D., Scarborough, C., Afflerbach, J. C., Frazier, M. R., O’Hara, C. C., ... Halpern, B. S. (2017). Our path to better science in less time using open data science tools. Nature Ecology \& Evolution, l(6), 0160. https://doi.org/10.1038/s41559-017-0160

Lowry, C. S., \& Fienen, M. N. (2013). CrowdHydrology: Crowdsourcing Hydrologic Data and Engaging Citizen Scientists. Ground Water, 51(1), 151-156. https://doi.org/10.1111/j.1745-6584.2012.00956.x

Lunghi, E., Corti, C., Manenti, R., \& Ficetola, G. F. (2019). Consider species specialism when publishing datasets. Nature Ecology \& Evolution, 3(3), 319. https://doi.org/10.1038/s41559-019-0803-8

Lupia, A., \& Elman, C. (2014). Openness in Political Science: Data Access and Research Transparency: Introduction. PS: Political Science \& Politics, 47(1), 19-42. https://doi.org/10.1017/S1049096513001716

McClean, T. (2011). Not with a Bang but a Whimper: The Politics of Accountability and Open Data in the UK (SSRN Scholarly Paper No. ID 1899790). Rochester, NY: Social Science Research Network. Retrieved from https://papers.ssrn.com/abstract $=1899790$

McCoy, M. D. (2017). Geospatial Big Data and archaeology: Prospects and problems too great to ignore. Journal of Archaeological Science, 84, 74-94. https://doi.org/10.1016/j.jas.2017.06.003

McKenna, E., Richardson, I., \& Thomson, M. (2012). Smart meter data: Balancing consumer privacy concerns with legitimate applications. Energy Policy, 41(C), 807-814.

Meyer, M. N. (2018). Practical Tips for Ethical Data Sharing. Advances in Methods and Practices in Psychological Science. https://doi.org/10.1177/2515245917747656

Michelsen, N., Dirks, H., Schulz, S., Kempe, S., Al-Saud, M., \& Schüth, C. (2016). YouTube as a crowd-generated water level archive. Science of The Total Environment, 568, 189-195. https://doi.org/10.1016/j.scitotenv.2016.05.211

Molina-Markham, A., Shenoy, P., Fu, K., Cecchet, E., \& Irwin, D. (2010). Private Memoirs of a Smart Meter. In Proceedings of the 2Nd ACM Workshop on Embedded Sensing Systems for Energy-Efficiency in Building (pp. 61-66). New York, NY, USA: ACM. https://doi.org/10.1145/1878431.1878446

Mueller, J., Loomis, J., \& González-Cabán, A. (2009). Do Repeated Wildfires Change Homebuyers' Demand for Homes in High-Risk Areas? A Hedonic Analysis of the Short and Long-Term Effects of Repeated Wildfires on House Prices in Southern California. The Journal of Real Estate Finance and Economics, 
38(2), 155-172. https://doi.org/10.1007/s11146-007-9083-1

Munafò, M. R., Nosek, B. A., Bishop, D. V. M., Button, K. S., Chambers, C. D., Percie du Sert, N., ... Ioannidis, J. P. A. (2017). A manifesto for reproducible science. Nature Human Behaviour, 1(1), 0021. https://doi.org/10.1038/s41562-016-0021

Naperville Smart Meter Awareness v. City of Naperville (United States Court of Appeals for the Seventh Circuit August 16, 2018). Retrieved from http://media.ca7.uscourts.gov/cgibin/rssExec.pl?Submit=Display\&Path=Y2018/D08-16/C:16-3766:J:Kanne:aut:T:fnOp:N:2203659:S:0

Perelman, L., \& Ostfeld, A. (2011). Topological clustering for water distribution systems analysis. Environmental Modelling \& Software, 26(7), 969-972. https://doi.org/10.1016/j.envsoft.2011.01.006

Powers, S. M., \& Hampton, S. E. (2018). Open science, reproducibility, and transparency in ecology. Ecological Applications. https://doi.org/10.1002/eap.1822

Prichard, J., Hall, W., de Voogt, P., \& Zuccato, E. (2014). Sewage epidemiology and illicit drug research: The development of ethical research guidelines. Science of The Total Environment, 472, 550-555. https://doi.org/10.1016/j.scitotenv.2013.11.039

Radin, J. (2017). "Digital Natives": How Medical and Indigenous Histories Matter for Big Data. Osiris, 32(1), 43 64. https://doi.org/10.1086/693853

Rainie, S. C., Rodriguez-Lonebear, D., \& Martinez, A. (2017). Policy brief: Indigenous data sovereignty in the United States. Tucson: Native Nations Institute, University of Arizona.

Resnik, D. B. (2018). The Ethics of Research with Human Subjects: Protecting People, Advancing Science, Promoting Trust (Vol. 74). Springer.

Resnik, D. B., \& Sharp, R. R. (2006). Protecting Third Parties in Human Subjects Research. IRB, 28(4), 1-7.

Rissman, A., Owley, J., L'Roe, A., Morris, A., \& Wardropper, C. (2017). Public access to spatial data on privateland conservation. Ecology and Society, 22(2). https://doi.org/10.5751/ES-09330-220224

Sankar, L., Rajagopalan, S. R., Mohajer, S., \& Mohajer, S. (2013). Smart Meter Privacy: A Theoretical Framework. IEEE Transactions on Smart Grid, 4(2), 837-846. https://doi.org/10.1109/TSG.2012.2211046

Scism, L. (2019, January 30). New York Insurers Can Evaluate Your Social Media Use-If They Can Prove Why It's Needed. Retrieved February 13, 2019, from https://www.wsj.com/articles/new-york-insurers-canevaluate-your-social-media-useif-they-can-prove-why-its-needed-11548856802

Seifert, C. A., Azzari, G., \& Lobell, D. B. (2018). Satellite detection of cover crops and their effects on crop yield in the Midwestern United States. Environmental Research Letters, 13(6), 064033. https://doi.org/10.1088/1748-9326/aac4c8

Sivapalan, M., Savenije, H. H. G., \& Bloeschl, G. (2012). Socio-hydrology: A new science of people and water. Hydrological Processes, 26(8), 1270-1276. https://doi.org/10.1002/hyp.8426

Srinivasan, V., Sanderson, M., Garcia, M., Konar, M., Blöschl, G., \& Sivapalan, M. (2017). Prediction in a sociohydrological world. Hydrological Sciences Journal, 62(3), 338-345. https://doi.org/10.1080/02626667.2016.1253844

Stack Whitney, K., Meehan, T. D., Kucharik, C. J., Zhu, J., Townsend, P. A., Hamilton, K., \& Gratton, C. (2016). Explicit modeling of abiotic and landscape factors reveals precipitation and forests associated with aphid abundance. Ecological Applications, 26(8), 2600-2610. https://doi.org/10.1002/eap.1418

Stagge, J. H., Rosenberg, D. E., Abdallah, A. M., Akbar, H., Attallah, N. A., \& James, R. (2019). Assessing data availability and research reproducibility in hydrology and water resources. Scientific Data, 6, 190030. https://doi.org/10.1038/sdata.2019.30

Stall, S., Robinson, E., Wyborn, L., Yarmey, L. R., Parsons, M. A., Lehnert, K., ... Hanson, B. (2017). Enabling FAIR Data Across the Earth and Space Sciences. Eos, 98. https://doi.org/10.1029/2017EO088425

Tulloch, A. I. T., Auerbach, N., Avery-Gomm, S., Bayraktarov, E., Butt, N., Dickman, C. R., ... Watson, J. E. M. (2018). A decision tree for assessing the risks and benefits of publishing biodiversity data. Nature Ecology \& Evolution, 2(8), 1209. https://doi.org/10.1038/s41559-018-0608-1

United Nations. (2018, January 4). Data Protection and Privacy Legislation Worldwide. Retrieved January 30, 2019, from https://unctad.org/en/Pages/DTL/STI_and_ICTs/ICT4D-Legislation/eCom-Data-Protection- 
Laws.aspx

United States of America v. Vargas (United States District Court, Eastern District of Washington December 15, 2014). Retrieved from https://cdn.arstechnica.net/wp-content/uploads/2014/12/sheaorder.pdf

Van Leuven, L. J. (2011). Water/Wastewater Infrastructure Security: Threats and Vulnerabilities. In R. M. Clark, S. Hakim, \& A. Ostfeld (Eds.), Handbook of Water and Wastewater Systems Protection (pp. 27-46). New York, NY: Springer New York. https://doi.org/10.1007/978-1-4614-0189-6_2

Vaz, E. M. de N. (2008). GIS from a cultural heritage perspective: when past and future collide (PhD Thesis).

Wagener, T., Sivapalan, M., Troch, P. A., McGlynn, B. L., Harman, C. J., Gupta, H. V., ... Wilson, J. S. (2010). The future of hydrology: An evolving science for a changing world. Water Resources Research, 46(5), n/a-n/a. https://doi.org/10.1029/2009WR008906

Whyte, K. (2017). What do indigenous knowledges do for indigenous peoples? Forthcoming in M. K. Nelson \& D. Shilling (Eds.), Keepers of the Green World: Traditional Ecological Knowledge and Sustainability. Rochester, NY. Retrieved from https://papers.ssrn.com/abstract=2612715

Wilkinson, M. D., Dumontier, M., Aalbersberg, Ij. J., Appleton, G., Axton, M., Baak, A., ... Mons, B. (2016). The FAIR Guiding Principles for scientific data management and stewardship. Scientific Data, 3, 160018. https://doi.org/10.1038/sdata.2016.18

Wu, F. T. (2013). Defining privacy and utility in data sets. U. Colo. L. Rev., 84, 1117.

Yu, D., Yin, J., \& Liu, M. (2016). Validating city-scale surface water flood modelling using crowd-sourced data. Environmental Research Letters, 11(12), 124011. https://doi.org/10.1088/1748-9326/11/12/124011

Zhou, X., \& Xu, C. (2017). Tracing the Spatial-Temporal Evolution of Events Based on Social Media Data. ISPRS International Journal of Geo-Information, 6(3), 88. https://doi.org/10.3390/ijgi6030088

Zipper, S. C. (2018). Agricultural Research Using Social Media Data. Agronomy Journal, 110(1), 349-358. https://doi.org/10.2134/agronj2017.08.0495

Zipper, S. C., Helm Smith, K., Breyer, B., Qiu, J., Kung, A., \& Herrmann, D. (2017). Socio-environmental drought response in a mixed urban-agricultural setting: synthesizing biophysical and governance responses in the Platte River Watershed, Nebraska, USA. Ecology and Society, 22(4). https://doi.org/10.5751/ES-09549220439

Zipper, S. C., Soylu, M. E., Booth, E. G., \& Loheide, S. P. (2015). Untangling the effects of shallow groundwater and soil texture as drivers of subfield-scale yield variability. Water Resources Research, 51(8), 6338-6358. https://doi.org/10.1002/2015WR017522 